\title{
Correlation of Nature of Amniotic Fluid with Maternal Risk on Neonatal Outcome at GMC, Ratlam
}

\author{
Devendra Nargawe ${ }^{1}$, Manish Rathore ${ }^{2}$ \\ ${ }^{1}$ Assistant Professor, Department of Paediatrics, Govt. Medical College, Ratlam, ${ }^{2}$ Senior Resident, Department of Paediatrics, Govt. Medical College, Ratlam.
}

\section{Abstract}

Background: After taking ethical clearance from hospital ethical board, this prospective study is being conducted at Govt. Medical College, Ratlam with a sample size of 149. All newborn babies born through MSAF will be included. Relevant history, clinical examination and relevant investigations would be done. Subjects and Methods: This prospective study is being conducted from 01/06/2016 to 01/6/2017 at Govt. Medical College, Ratlam with a sample size of 149. All newborn babies born through MSAF will be included. Relevant history, clinical examination and relevant investigations would be done. Results: Average number of maternal risk factors is 18(12\%); of which 9 cases $(6.82 \%)$ belong to thin MSL and 9 cases (50\%) belong to thick MSL. The mean difference between two groups is statistically significant ( $\mathrm{p}$ value $=.000)$. It comprises: PIH-13 cases $(8.67 \%)$ of which 5 cases $(3.79 \%)$ are thin MSL and 8 cases (44.4\%) belong to thick MSL; Oligohydraminos- 3 cases (2\%), all 3 cases (2.27\%) are from thin MSL and 0 case from thick MSL;GDM-2 cases(1.34\%),thin MSL comprises 1 case $(0.76 \%)$ and thick MSL comprises 1 case $(5.55 \%)$. Conclusion: Meconium stained liquor is more commonly associated with PIH, postdatism, oligohydroamnios and DM, etc. Risk factors which were associated with MSAF were PIH in $8.67 \%$, oligohydramnios in $2 \%$ of the cases, GDM in $1.34 \%$ cases. ( $\mathrm{p}$ value $=.000$ ), which is significant.

Keywords: Amniotic Fluid, Maternal Risk, Neonatal \& Outcome.

Corresponding Author: Dr. Manish Rathore, Senior Resident, Department of Paediatrics, Govt. Medical College, Ratlam.

Received: December 2018

Accepted: December 2018

\section{Introduction}

Lightly stained meconium had a poor correlation with fetal hypoxia. ${ }^{[1]}$ MAS is more frequently seen in post term pregnancy or in growth restricted fetuses.Factors such as placental insufficiency,maternal hypertension, preeclampsia, oligohydroamnios or maternal drug abuse (tobacco or cocaine) result in, in utero passage of meconium. ${ }^{[2]}$

Amniotic fluid (AF) is a biological medium uniquely suited for the study of early exposure of the human fetus to environmental contaminants acquired by the mother before and during pregnancy. Traditional diagnostic applications of AF have focused almost exclusively on the diagnosis of genetic aberrations. ${ }^{[3]}$

\section{Subjects and Methods}

After taking ethical clearance from hospital ethical board, this prospective study is being conducted from 01/06/2016 to $01 / 6 / 2017$ at Govt. Medical College, Ratlam with a sample size of 149. All newborn babies born through MSAF will be included. Relevant history, clinical examination and relevant investigations would be done.

\section{Inclusion Criteria:}

- All singleton babies born with meconium stained liquor in the hospital during the study period.

- All those who had given consent.

\section{Exclusion Criteria:}

- Babies born at < 34 completed weeks of gestation.

- Absence of meconium in the amniotic fluid.

- Respiratory distress due to other etiologies.

- Presence of major congenital anomaly.

- Still born babies.

- Twin deliveries.

All neonates included in the study will have the following done:

1. Detailed maternal history like age, parity, LMP, EDD, LPV, BPV, immunization status, gestational age, caste, infection, hypertension, nature of amniotic fluid, drugs will be noted.

2. Details of labour, mode of delivery, presence of complications if any will also be recorded.

3. Thorough clinical examination of the neonates will be done. 


\section{Nargawe \& Rathare; Carrelation of Nature of Amniatic Fluid with Maternal Risk}

\section{Results}

Average number of maternal risk factors is $18(12 \%)$; of which 9 cases $(6.82 \%)$ belong to thin MSL and 9 cases $(50 \%)$ belong to thick MSL.The mean difference between two groups is statistically significant ( $\mathrm{p}$ value $=.000$ ).
It comprises: PIH-13 cases (8.67\%) of which 5 cases $(3.79 \%)$ are thin MSL and 8 cases $(44.4 \%)$ belong to thick MSL; Oligohydraminos- 3 cases (2\%), all 3 cases $(2.27 \%)$ are from thin MSL and 0 case from thick MSL;GDM-2 cases(1.34\%),thin MSL comprises 1 case $(0.76 \%)$ and thick MSL comprises 1 case $(5.55 \%)$.

\begin{tabular}{|c|c|c|c|c|c|c|c|c|}
\hline $\begin{array}{l}\text { Nature of } \\
\text { amniotic } \\
\text { fluid }\end{array}$ & $\begin{array}{l}\text { Number } \\
\text { of cases } \\
\text { with PIH }\end{array}$ & $\begin{array}{l}\text { Percentage } \\
\text { of cases with } \\
\text { PIH }\end{array}$ & $\begin{array}{l}\text { Number of cases } \\
\text { with } \\
\text { Oligohydraminos }\end{array}$ & $\begin{array}{l}\text { Percentage of cases } \\
\text { with } \\
\text { Oligohydraminos }\end{array}$ & $\begin{array}{l}\text { Number } \\
\text { of cases } \\
\text { with } \\
\text { GDM }\end{array}$ & $\begin{array}{l}\text { Percentage } \\
\text { of cases with } \\
\text { GDM }\end{array}$ & $\begin{array}{l}\text { Average } \\
\text { number of } \\
\text { maternal } \\
\text { risk } \\
\text { factors }\end{array}$ & Total \% \\
\hline Thin MSL & $5 / 131$ & $3.81 \%$ & $3 / 131$ & $2.29 \%$ & $1 / 131$ & $0.76 \%$ & $9 / 131$ & $6.87 \%$ \\
\hline Thick MSL & $8 / 18$ & $44.4 \%$ & $0 / 18$ & $0 \%$ & $1 / 18$ & $5.55 \%$ & $9 / 18$ & $50 \%$ \\
\hline
\end{tabular}

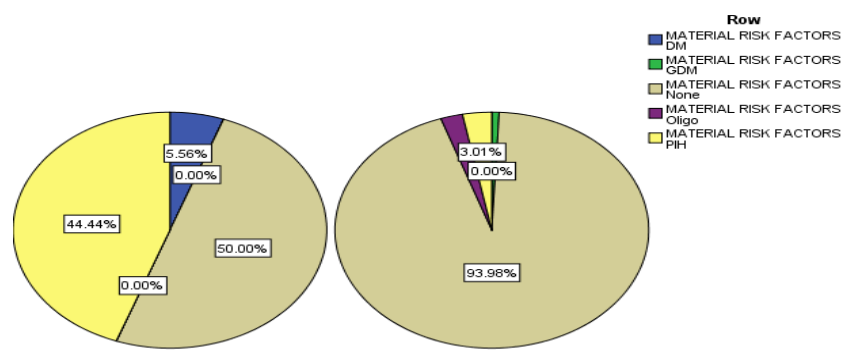

NATURE of AMNIOTOC FLUID NATURE of AMNIOTOC FLUID
thick Column N\%

Column

Figure 1: Correlation of nature of amniotic fluid with maternal risk factors.

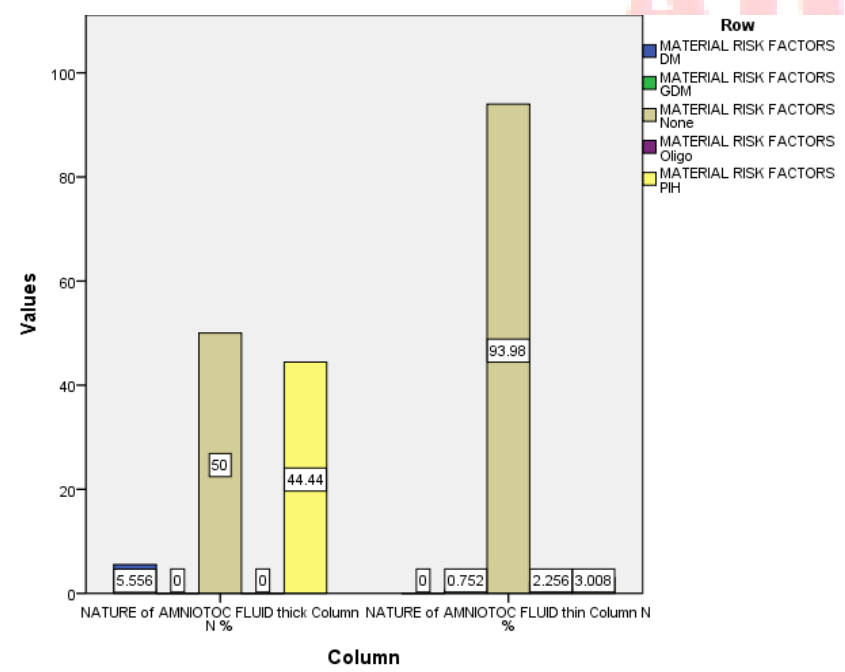

Figure 2: Correlation of nature of amniotic fluid with maternal risk factors

\section{Discussion}

Maternal risk factors: Average number of maternal risk factors is $18(12 \%)$.It comprises: PIH, Oligohydraminos,
GDM. The p value is .000 which is stastically significant. Desmond4, Fujikura 5 concluded that actual causes or factors which control meconium passage are due to diminished $\mathrm{O} 2$ transfer, toxemia, hypertension, anemia, obesity, type of labour, maternal age, prolonged gestation were associated with high incidence of meconium passage.Meis6 (1978) observed that in pre-eclampsia incidence of meconium staining was three times more than control group, in prolonged labour two fold incidence. Our findings are consistent with the findings of Fujikura and Meis. ${ }^{[5,6]}$

In Casey et al, ${ }^{[7]}$ the mean maternal age was 23.9 years which is comparable to the present study. In Donald D et $\mathrm{al}^{\left[{ }^{[8]}\right.}$ the incidence of oligohydramnios was $60 \%$ in primigravida which is comparable to present study as it was $52 \%$. Sir Gangaram Hospital study shows 68\% vaginal deliveries in induced patients of Oligohydramnios and $32 \%$ by caesarean section which is comparable to our study. ${ }^{[9]}$ Manzanares $\mathrm{S}$ et al, ${ }^{[10]}$ shows $84 \%$ vaginal deliveries in induced patients of Oligohydramnios and $16 \%$ by caesarean section. In this study, in spite of non-reactive NST $25 \%$ patients delivered vaginally. The caesarean section was done more commonly in 755 patients with non-reactive NST as seen in Charu Jandial study. ${ }^{[1]}$ As these patients had oligohydramnios, a non-reactive NST + AFI $<5$ indicated fetal jeopardy as per revised Biophysical profile scoring by Clerk et al. ${ }^{[12]}$ The fetal jeopardy was reflected as increase operative interference in this study.

\section{Conclusion}

Meconium stained liquor is more commonly associated with PIH, post-datism, oligohydroamnios and DM, etc. Risk factors which were associated with MSAF were PIH in $8.67 \%$, oligohydramnios in $2 \%$ of the cases, GDM in $1.34 \%$ cases. $(\mathrm{p}$ value $=.000)$, which is significant. 


\section{Nargawe \& Rathare; Carrelation of Nature of Amniatic Fluid with Maternal Risk}

\section{References}

1. Ratnam SS, Bhaskar Rao K, Arulkumaran S. Practical approach to Intrapartum fetal monitoring in labour. Chapter 12. Obstetrics and Gynecology for Postgraduates 1992.

2. Steer PJ, Danielian P. Fetal distress in labour. In: James OK, Steer PJ, Weiner CP, Gonick B (eds). High risk pregnancy 2nd ed. New York WB Saunders Company 2000; pp 1135-40

3. Laura A. Geer, Benny F. G. Pycke, Environ Res. 2015 Jan; 0: 470-481.

4. Desmond MM, Lindley JE, Moore J, Brown CA. Meconium staining of newborn infant. J Pediatr 1956; 49:540

5. Fujikura T, Klionsky B. The significance of meconium staining. Am. J. Obstet. Gynecol. 1975; 121:45-49.

6. Meis Paul J, Hall III M, Marshall JR, Hobel CJ. Meconium passage: A new classification for risk assessment during labour. Am. J. Obstet. Gynecol. 1978; 31:509-513.

7. Casey BM, McIntire DD, Bloom SL, Lucas MJ, Santos R, Twickler $\mathrm{DM}$, et al. Pregnancy outcomes after antepartum diagnosis of oligohydramnios at or beyond 34 weeks' of gestation. Am J Obstet Gynecol 2000;182(4):909-12.

8. Petrozella LN, Dashe JS, McIntire DD, Leveno KJ. Clinical Significance of Borderline Amniotic Fluid Index and Oligohydramnios in Preterm Pregnancy. Obstetrics \& Gynecology 2011;117(2 Pt 1):33842.

9. Umber A. Perinatal Outcome in Pregnancies Complicated by Isolated Oligohydramnios at Term. Annals 2009;15:35-37.

10. Manzanares S, Carrillo MP, González-Perán E, Puertas A, Montoya F. Isolated oligohydramnios in term pregnancy as an indication for induction of labor. J Matern Fetal Neonatal Med. 2007;20(3):221-4.

11. Jandial C, Gupta S, Sharma S, Gupta M. Perinatal Outcome After Antepartum Diagnosis of Oligohydramnios at or Beyond 34 Weeks of Gestation. JK SCIENCE 2007;9(4):213-14.

12. Clark SL, Sabey P, Jolley K. Nonstress testing with acoustic stimulation and amniotic fluid volume assessment: 5973 tests without unexpected fetal death. Am J Obstet Gynecol 1989;160(3):694-7.

Copyright: () the author(s), 2019. It is an open-access article distributed under the terms of the Creative Commons Attribution License (CC BY 4.0), which permits authors to retain ownership of the copyright for their content, and allow anyone to download, reuse, reprint, modify, distribute and/or copy the content as long as the original authors and source are cited.

How to cite this article: Nargawe D, Rathore M. To Correlation of Nature of Amniotic Fluid with Maternal Risk on Neonatal Outcome at GMC, Ratlam. Asian J. Clin. Pediatr. Neonatol.2019;7(1):5-7.

DOI: dx.doi.org/10.21276/ajcpn.2019.7.1.2

Source of Support: Nil, Conflict of Interest: None declared.

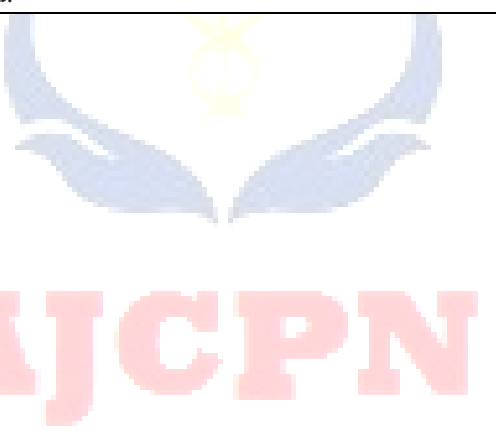

